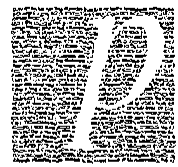

\title{
Patologias y contagios literarios
}

\author{
Adriana Gorzález Mateos
}

\author{
New York University
}

Los contagios literarios aludidos por el titulo se refieren a un tópico presente en la literatura francesa e inglesa de finales del siglo XIX: es el contagio de una perversión por medio de las paiginas de un "Iibro emponzoñado" que se convierte en un seductor y en un maestro para cambiar la vida del hasta entonces inocente lector, como tuvo que lamentar el incauto Dorian Gray. Cuando esa perversion es la homosexualidad y el venenoso libro la contagia por medio de alusiones, sobrcentendidos e insinuaciones, ya que tal patologia no puede decir su nombre y debe velarse con todo tipo de disfraces, nos encontramos ante un muy particular uso de la literatura, que se convierte en un lenguaje cifrado entre iniciados. Esie articulo analiza dos brotes hispanoamericanas de semejantes infecciones librescas: ios "subterfugios" empleados par Manuel Mujica Lainez para cifrar su mensaje infeccioso en la Argentina de los años 40, tomando como ejemplo un cuento de Misteriosa Buenos Aires, y la evolución del contagio literario entre dos jóvenes poetas mexicanos de los años veinte, Salvador Novo y Xavier Villaurutia.

A ientras la literatura médica de finales del siglo $X I X$ se afanaba por describir las 1 conductas sexuales para categorizarlas como patologias, y establecia un inventario de sus origenes, sintomas y caracteristicas, en el universo literario se

\section{Poligrafias IV (2003) 167-377}

(1) Poligrafias. Revista de Literatura Companada. División de Estudios de Posgrado, Facultad de

Filosofia y Letras, Universidad Nacional Autònoma de México, Ciudad Universitaria, México 04510 of Tcl. (525) $6221835(6)$. Fax $(525) 6221801 ; 6160047 ; 6221826$ 
producía un fenómeno quizá parelelo: los libros empezaron a ser considerados agentes patógenos, verdaderos vehículos de contagio. Es imposible no recordar los efectos de un "poisonous book" de tapas amarillas en la vida de Dorian Gray, frecuentemente interpretado como una referencia a $A$ rebours, aunque el narrador de Wilde no mencione su título (Ellmann 1988, 252). La novela de Huysmans describe el proceso de lectura como una influencia que requiere una proximidad, espiritual si se quiere, pero casi íntima, entre escritor y lector:

le roman ainsi conçu (...) deviendrait une communion de pensée entre un magique écrivain et un idéal lecteur, une collaboration spirituelle consentie entre dix personnes supérieures éparses dans l'univers, une delectation offerte aux délicats, accesible à eux seuls. (Huysmans 1972, 245)

El paso metafórico entre esta delectación y el envenenamiento lo dio Wilde; el otro, que media entre el veneno y la patología, no tardó en hacerse evidente en otros textos de índole muy distinta. Llama la atención la inclusión de la sensibilidad artística y la ambición literaria entre los síntomas reunidos para diagnosticar a un paciente, a la vez, como "literato" y como "maricón" (Molloy 1998, 153-154) en la Argentina finisecular; Gómez de Baquero, corresponsal de El Nacional en París, informaba a los lectores mexicanos interesados en los juicios de Oscar Wilde que

Tal vez no haya tanta distancia como se piensa entre las observaciones mentales y las depravaciones fisicas. El afán de buscar estimulantes intelectuales en lo monstruoso, en lo anormal, en lo extraordinario, puede pasar de la teoría a la práctica. El caso de Oscar Wilde es quizá un caso de patología literaria... Es posible que haya en este asunto tan repugnante un aviso a los partidarios de las escuelas decadentes que no quieran llegar, en su decadencia, hasta el amor griego. (El Nacional, 8 de mayo de 1895, citado por Irwin 2000, 125)

Para entender mejor cómo sería esta forma de lectura, que llegaría a ser vista como fuente de contagio, vale la pena recordar otro antecedente del envenenamiento de Dorian Gray, aunque en este caso el lector infectado fue consumido por una enfermedad que él quiso disfrazar de suicidio: hablo del protagonista de The Portrait of $M r$.W.H., tan afecto a las lecturas dobles, las hipótesis, la interrogación imaginativa e infatigable de claves textuales interpretadas como pistas hacia el misterio. Un muy similar gusto por citas, alusiones literarias, pastiches, referencias y otras prácticas textuales que requieren del lector una disposición a leer como si descifrara un significado que no es evidente en la primera lectura, sino que está cuidadosamente oculto, señalado y aludido por claves que pueden hallarse si se dispone de cierta paciencia e información, ha sido considerado característico de varios escritores hispanoamericanos de la primera mitad del siglo XX, cuya escritura muestra síntomas de malestar o incomodidad relacionados con asuntos sexuales (Molloy inédito). La sección titulada "Canto a Teresa" dentro de Continente vacio, de Salvador Novo, es un excelente ejemplo de esta práctica; "Memorias de Pablo y Virginia," de Manuel Mujica Lainez, incluído en Misteriosa Buenos Aires, ofrece otra inmejorable ocasión 
de describir este uso de alusiones y recursos oblicuos para sugerir un significado oculto, una lectura paralela, que la historia jamás aclara.

El narrador de "Memorias de Pablo y Virginia" no es una "voz" sino el célebre libro del mismo nombre, el cual se presenta con un comentario lleno de reserva, que vagamente apunta a su ambigüedad de género: "Me llamo Pablo y Virginia. Esto otorga a mi personalidad yo no sé qué de ambiguo" (Mujica Lainez 1968, 161). Estas líneas culminan una larga meditación sobre la vida oculta de los objetos y su lenguaje siempre mal entendido, que a su vez sugiere la necesidad de adivinar qué puede estar más allá de lo que se dice explícitamente. Vale la pena señalar dos detalles: primero, aunque éste no es un "libro emponzoñado," sí es un libro infectado, pues alberga parásitos que lentamente corroen sus páginas; segundo, se trata de una traducción española del original francés; en otras palabras, es el resultado de una lectura sofisticada, que ha alterado el texto original. Éste es el narrador que comienza por reconocer que Paul et Virginie, la novela de Bernardin de Saint-Pierre a partir de la cual fue traducido, es una obra literaria mediocre, y por atribuir su falta de interés precisamente a su estilo franco y directo: "Es una historia, lo declaro rotundamente, sin subterfugios, que no me interesa" (162); más aún, "Mi padre describe bien, acaso demasiado bien, pero sus conocimientos psicológicos me parecen rudimentarios" (162). En varios pasajes el narrador se mofa de la habilidad descriptiva, precisamente porque consiste en referir lo aparente de manera fiel. La afición por la franqueza tiene que ver con la intención declarada por Saint-Pierre: "Bernardin de Saint-Pierre declara su propósito de dedicar su libro a poner en evidencia algunas hondas verdades, entre otras aquella de que la felicidad finca en vivir de acuerdo con la naturaleza y la virtud" (178), intención llevada a cabo por medio de una historia de amor que se supone destila la quintaesencia de lo natural: "la anécdota de una pareja semisalvaje que se amó con ingenuidad y que murió por amor, entre los cocoteros, los papagayos y los tatamaques de una isla africana" (162).

La ironía evidente en las líneas anteriores es reforzada por los distintos lectores que, a lo largo del cuento, tienen la oportunidad de expresar sus opiniones sobre esta trama. Si el narrador los considera interesantes o inteligentes, la lectura los aburre mortalmente: "El Hermafrodito me hablaba de Temístocles y de Jerjes. Yo, por corresponder a su cortesía, le referi la historia de Virginia y Pablo, pero poco a poco advertí que una sombra de tedio cubría sus ojos" (166); los pocos que se interesan en la historia son estúpidos o ignorantes: "mi sinceridad me obliga a consignar la atención con que espié en su rostro los pucheros y las beatas sonrisas que marcaron, hasta el llanto final, su progreso en la lectura" (169). Pero la historia de amor heterosexual no sólo es aburrida: es manipuladora y artificial, según otro personaje que anota en los márgenes: "B. de S.P. no vivió ni según la naturaleza ni según la virtud. Fue un cortesano ambicioso que sacrificó todo a su egoísmo. Científicamente no encierra ningún interés. Humanamente, tampoco" (179).

Eso por lo que respecta a las "historias sin subterfugios," a la sinceridad y a las virtudes evidentes. En cambio, Mujica Lainez desarrolla técnicas de narración alusiva. El cuento narra, entre otros episodios, el viaje de dos jóvenes caballeros victorianos a 
través de Europa, dos dandies. La limitada perspectiva del narrador, que sólo puede referir lo que sucede en su presencia, permite una revelación gradual de la naturaleza de la relación entre estos dos personajes a través de los objetos que los rodean; una descripción que, tras detallar lo visible, apunta por analogía a aquello que debe ser adivinado. Además de la traducción de Paul et Virginie (cuyo género es indeciso), y de una estatua griega de Hermafrodito, los ingleses llevan anillos "extraños" " "secretos." Estos adjetivos siguen un principio de contagio metonímico: "extraño" o "raro" es un adjetivo que con frecuencia se usa para describir a gente homosexual; "secreto" alude a esta sexualidad, que debe ocultarse; por último, los personajes "hablan de Grecia" (como se recordará, Gómez de Baquero usa la frase "amor griego" como eufemismo para referirse a la homosexualidad). Tantos detalles acumulados informan a lectores y lectoras (si están al tanto de los significados menos evidentes y por esta razón se distinguen de los lectores ingenuos descritos en el cuento; en otras palabras, si están dispuestos a ejercer, ellos también, cierta lectura oblicua) de la relación homosexual entre los dos ingleses:

Colmaba buena parte de su espacio libre, frente al asiento, una estatua de mármol protegida por una armazón de madera, de la cual los jóvenes no querían separarse: el Hermafrodito de Salamina. Por él supe, pues pronto anudamos la charla en un cuasi francés equidistante, que se había sumado a la comitiva meses atrás.(...) Nada de cuanto diga acerca de su hermosura logrará reflejarla. A veces, mientras proseguíamos nuestro avance demente, un rayo de luna se filtraba por los vidrios de la portezuela y encendia el torso maravillosamente blanco, los mirtos enlazados en sus sienes, la paloma acurrucada en su hombro. Sir Clarence y Lord Gerald se tomaban entonces de las manos alhajadas con extraños anillos secretos, y hablaban de Grecia. (165)

El desenlace del episodio es narrado de acuerdo con este método de "subterfugio": en vez de relatar el ataque sufrido por los dandies, asaltados por un grupo de bandidos españoles, el narrador lamenta la suerte de la estatua, arrojada a un precipicio porque nadie puede determinar su género. De esta manera, la homosexualidad y la violencia dirigida contra ella, aunque al parecer ocultas, resultan subrayadas por la reticencia empleada al narrarlas. El interés de la lectura no reside tanto en la anécdota, sino en la sagacidad necesaria para captar los distintos niveles de lo dicho, discriminar las claves, imaginar lo oculto, rasgos que contribuyen a caracterizar un gusto literario, ciertamente y por estas razones, sofisticado, estructurado en torno a ciertas prohibiciones y a los juegos que las mantienen y las desafian. En cierto modo, tal como la versión española de Paul et Virginie es una especie de doble de la obra original, este cuento es una narración de las anécdotas presentes en la página, pero también algo distinto, que el lector recompone a partir de ciertas indicaciones. Es un texto que lleva una doble vida.

Pese al innegable encanto que le prestan tales "subterfugios," esta literatura de la alusión y la reticencia entraña dificultades que Salvador Novo expone con claridad en uno de los poemas de Espejo, que data de 1933 (1977, 73), donde sintetiza las convenciones ideológicas vigentes en la poesía que conoció en su infancia: 
para ser un poeta de vida apasionada y romántica

cuyos libros están en las manos de todos

$[\ldots]$

es necesario decir las cosas que leo,

esas del corazón, de la mujer y del paisaje,

del amor fracasado y la vida dolorosa,

en versos perfectamente medidos,

sin asonancias en el mismo verso,

con metáforas nuevas y brillantes.

Aunque la habilidad técnica para medir los versos y crear las metáforas le parece un juego de niños,

Tendré una habilidad de histrión

para hacerles creer que me conmueve lo que a ellos.

Pero en mi lecho, solo, dulcemente,

sin recuerdos, sin voz,

siento que la poesía no ha salido de mí.

Además de sugerir una semejanza entre esta poesía que no llega a expresarse y una emisión sexual reprimida por el púber solo en su cama, este poema define el conflicto entre lo que puede hacerse público, pero es experimentado como histriónico, lo que debe ser aludido por medios oblicuos (la homosexualidad, ya que la poesía aceptable habla de la mujer) y lo que, al estar condenado al secreto, está destinado a ser reprimido o eliminado. Como resultado, las convenciones literarias quedan huecas y empiezan a erosionarse. Es la situación que da origen al camp.

Mujica Lainez hace una "visita guiada" por su casa de campo y comenta con uno de los invitados:

“No piensa poner cisnes en el lago?

"No; pienso hacer fabricar una Ofelia de material plástico, de largos cabellos rubios, plásticos también, que flotarán en torno. Tendrá un oculto motorcito, que le permitirá desplazarse entre los juncos, cruzados los brazos, la mirada ausente. Será una apoteosis de Shakespeare, a quien he traducido, y de Rimbaud, a quien tanto quiero. ¿Recuerda usted?

Sur l'onde calme et noire où dorment les etoiles, La blanche Ophelia flotte comme un grand lys...

Y Ofelia, exhalando un apagado ¡tuf tuf! ¡tuf tuf?, que hará las veces de sus últimos estertores, la plástica Ofelia, sostenida mecánicamente en la liquida superficie, se alejará, haciendo la plancha, bajo los sauces. Será muy conmovedor. $(1994,78)$

Esta escena declara obsoleto al canon literario y lo embalsama para convertirlo en un espectáculo mecánico, pero también se burla del propio Mujica Lainez, traductor y admirador de Shakespeare, y de sus emociones frente a textos poéticos que alguna vez le sirvieron de inspiración. La escena podrá repetirse interminable y trivial; los rasgos que dieron su carácter conmovedor al pasaje original se caricaturizan para despojarlos 
de su significado, como la mirada ausente de Ofelia, convertida en la mirada vacía de una muñeca de plástico. Pero, como apunta el poema de Novo, la distancia emocional lograda por medio de esta agresión irónica no sólo corroe las convenciones literarias al denunciarlas como represivas, sino que entraña la amenaza del silencio, ya que todo lo que puede decirse debe pasar por esta lente sardónica con tal de sobrevivir a la agresión circundante. Vale la pena recordar la definición del camp dada por Carlos Monsiváis:

Hans Meyer ve en la estetización de los problemas morales la primera vía de legitimación de lo "socialmente inmoral." Si lo anterior no es criterio exclusivamente homosexual en las sociedades incapaces de concederle utilidad espiritual al arte, sí determina la sensibilidad artificial que es "decadentismo" en el siglo XIX, y en el siglo $\mathrm{XX}$ es el camp (...) Esto (...) explica la técnica del artificio, el engaño dentro del engaño, el escamoteo de la tragedia por el patetismo con final sardónico, la ironía que se burla de los méritos propios para neutralizar el linchamiento moral, la ferocidad a costa de lo que se ama (y que por lo mismo se está dejando de amar) el travesti como inventor de la realidad que termina imitándolo, la parodia que ridiculiza al mismo tiempo al objeto parodiado y al sujeto escarnecedor. (2000,83-84)

El problema se comprende aún mejor gracias a algunos incidentes narrados con una perspectiva autobiográfica en La estatua de sal. Es interesante puntualizar que estas memorias fueron escritas en 1945, tres años antes de que Mujica Lainez empezara a componer los cuentos de Misteriosa Buenos Aires. Se trata, pues, de dos obras estrictamente contemporáneas, cuya comparación es útil para esclarecer el alcance y las consecuencias prácticas de las prohibiciones que establecen qué puede escribirse y qué debe callarse, qué puede conmover y qué debe ser dicho bajo la protección del subterfugio o la ironía.

La estatua de sal narra el papel desempeñado por los ejercicios literarios en la educación sentimental y sexual de dos adolescentes mexicanos, Salvador Novo y Xavier Villaurrutia. Para estos personajes, las relaciones entre la literatura y la sexualidad son complejas, invadidas por una contradictoria necesidad de revelación y secreto. Los adolescentes Novo y Villaurrutia se hacen amigos porque ambos escriben poesía; pronto comparten las lecturas centrales del canon homosexual de la época (Gide, Huysmans, Wilde) y leen El retrato de Dorian Gray (evidentemente en una versión española) "con culpable fruición admirativa." Esta obra es una especie de intermediario para ellos - "La conversación a propósito de Wilde fue acercándonos a la confidencia" (101) - y hace posible que, al cabo, hablen francamente de sus sexualidades; para llevar más lejos el contagio literario, es sólo a través de una carta que Villaurrutia finalmente confiesa la suya (101), un acto que Novo narra con palabras sexualmente cargadas, llamándolo "su entrega." No es sorprendente, pues, que el joven Novo ampliara sus experiencias sexuales por medio de la escritura de una "minuciosa y romántica autobiografía novelada que titularía Yo" (113) caracterizada por "su crudeza, su sinceridad, la mención de los nombres auténticos," pero que le pareciera necesario mantener el manuscrito encerrado bajo llave. Para Villaurrutia, que "no parecía haber descubierto sus tendencias," la mera existencia del manuscrito era tan alarmante que forzó el candado para apoderarse de él, acto que Novo resintió como 
una pérdidad de la virginidad (113). Al cabo, ambos destruyeron las confesiones del otro por medio de actos que, de un modo $u$ otro, son revelaciones: Villaurrutia, al robar y leer el manuscrito de Novo; Novo, al prestar las cartas de Villaurrutia a alguien que las pierde.

Como se sabe, estas anécdotas prefiguran la suerte de La estatua de sal, que permaneció inédita durante cincuenta y tres años. Estas memorias de Salvador Novo, que en cierto modo son una reescritura de aquella primera autobiografia adolescente y reproducen su franqueza, se convirtieron en un "secreto a voces," que por sabido se callaba: un manuscrito inédito, algunas veces leído en público, que llegó a tener cierta fama, se publicó tras la muerte de Novo en la revista Nuestro cuerpo y en versión al inglés (incluida en la antología Now the Volcano) pero siguió siendo inaccesible en su forma original en español hasta 1998. Misteriosa Buenos Aires, en cambio, fue escrita entre 1948 y 1950, publicada inmediatamente por Editorial Sudamericana y llevada al cine en los años ochenta (De la misteriosa Buenos Aires, dirigida por Wulicher, Fischerman y Barney Finn). La recepción de esta obra fue, hasta cierto punto, doble: causó un modesto escándalo, pues de acuerdo con Alberto Manguel, las tías de Mujica Lainez se sintieron perturbadas por su violencia y ofrecieron un Te Deum por el alma del autor, pero al cabo de los años, uno de los cuentos ("El hombrecito del azulejo") acabó por convertirse en un clásico de la literatura infantil. Es reproducido con grabados, cupones que ofrecen premios y textos de intención didáctica, que pretenden entrenar a los niños en el trato con la literatura, como puede comprobarse al revisar el volumen de ese título publicado por Sudamericana en su colección Pan Flauta.

En pocas palabras, el tópico del libro ponzoñoso refleja el proceso por el cual la homosexualidad fue clasificada como patología, pero guarda también la memoria de los padecimientos que esto trajo consigo para quienes necesitaron convertirla en tema literario. La necesidad de escribir en clave funcionó maravillosamente como metáfora del contagio: gracias a esta práctica, el libro ocultó, bajo su apariencia inocua, la narración de la patología y las huellas de la censura.

Pero, ¿cómo sería esa poesía tan tenazmente silenciada por las convenciones literarias y la censura, esa poesía, que, según Novo, "no ha salido de mi"? En las páginas anteriores me he detenido en ejemplos que apuntan a las restricciones impuestas por las convenciones literarias y la censura en sus distintos niveles, desde el adolescente que se asegura de encerrar su manuscrito con candado pasando por el amigo que se preocupa por controlar ese descaro y el escritor que recurre al subterfugio, hasta las generaciones que prolongan el silencio. Antes de terminar me detendré brevemente en otro nivel del conflicto, es decir, las coincidencias entre enemigos al parecer irreconciliables: el pintor revolucionario que denuesta los vicios de la burguesía y el esteta burgués caricaturizado por él, José Clemente Orozco (ver Figura 1) y Salvador Novo. Pese a sus posiciones antagónicas, ambos describen imágenes coincidentes de la homosexualidad y una vez más la asocian con la poesía y con los libros. No es necesario decidir si la descripción de Novo utiliza términos negativos porque el poeta ha asimilado los ataques de sus enemigos o porque, de acuerdo con el narrador de The Picture of Dorian Gray (para quien la insinceridad es 
"merely a method by which we can multiply our personalities" Wilde 1946, 300), en este poema ensaya como un histrión los denuestos que le permiten mostrarse contrito, patético, culposo, etcétera. Es más interesante observar hasta qué punto un ataque y una autodefinición llegan a ser casi simétricos en su uso de las convenciones ideológicas reinantes.

Las coincidencias comienzan con las manos, que a lo largo de la obra de Novo sirven para aludir metonimicamente al cuerpo homosexual. El último poema de Nuevo amor describe y define a

Los que tenemos unas manos que no nos pertenecen, grotescas para la caricia, inútiles para el taller o la

azada,

largas y fláccidas como una flor privada de simiente o como un reptil que entrega su veneno porque no tiene nada más que ofrecer.

A su vez, el grabado de Orozco insiste en la ondulación de las manos de los personajes: como si quisiera contribuir a la tradición mexicana que inventa eufemismos que las aluden para referirse a un homosexual ("los que cachan granizo," "los que juegan tenis sin raqueta," "Jos que perdieron la charola"), Orozco multiplica los gestos de las manos, una de las cuales sostiene una flor, otras ajustan un peinado o un sombrero, otras se dirigen a las nalgas de otras figuras. El personaje central parece

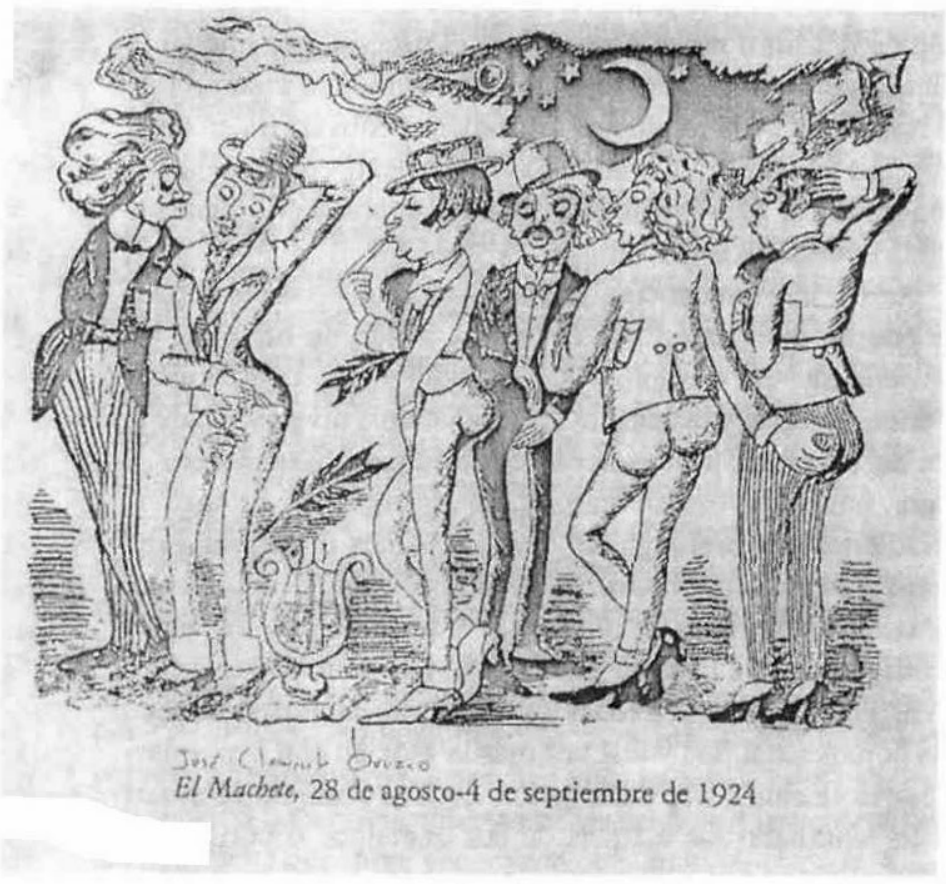

Figura 1

dibujado con la intención de subrayar la carga erótica de las manos, pues toca sus genitales con una, como si fuera a masturbarse, mientras chupa lúbricamente un dedo de la otra, lo cual sugiere tanto su esterilidad como su e gocentris mo; además, sostiene una pluma y un libro, que lo caracterizan como poeta. El poema también insiste en la esterilidad de la poesía y en su inutilidad para trascender la soledad, pues concluye que la música ("toda la música del universo," 
otra coincidencia con la lira del grabado) y la poesía relacionada con ella están "vacías," son una voz que no escucha nadie, en un lenguaje soñado, descrito como frágil y efimero ("la lengua de la arcilla y del humo"). Tanto en el grabado como en el poema las manos son largas y ondulantes ("largas y fláccidas"), semejan flores (uno de los personajes de Orozco sostiene una) o serpientes (véanse las curvas sinuosas de las manos en el grabado). En ambos casos, las manos son claramente ineptas para el trabajo rudo y varonil ("inútiles para el taller o la azada") y Orozco muestra que sus instrumentos favoritos son plumas, libros, quizá una lira. Novo elabora la metáfora de la serpiente, que al mismo tiempo alude metafóricamente a un pene: las manos son sinuosas pero también estériles, potencialmente dañinas porque eyaculan veneno, al contrario de las manos que se unen en matrimonio ("porque no podrá nunca cerrarse sobre los anillos de oro") y engendran niños:

mientras los hombres van trabajosamente ascendiendo

y brotan otras manos de sus manos para torcer el rumbo

de los vientos

o para tiernamente enlazarse.

La esterilidad ("una flor privada de simiente") también es sugerida en el grabado, donde el personaje central se toma los genitales como para masturbarse. Las manos de estos personajes podrían muy bien describirse como "grotescas para la caricia," como la que sostiene la flor, con sus exageradas curvas y el retorcimiento de sus dedos. Tanto el grabado, con su agresivo lenguaje visual, como el poema, con la progresión decreciente de su final melancólico

y no veremos nunca con nuestros ojos limpios

otro día que este día en que toda la música del

universo

se cifra en una voz que no escucha nadie entre las

palabras vacías

$y$ en el sueño sin agua ni palabras en la lengua de la

arcilla y del humo

implican la esterilidad del arte, al menos del arte producido por los sujetos homosexuales aludidos por ambos.

El grabado insiste en la elegancia del grupo para caracterizarlo como un grupo burgués; algunos elementos provienen de la tradición de los dandies europeos, como el pelo largo y ondulante de tres personajes. Pero sobre todo, la imagen los asocia con accesorios propios de los poetas: además de la lira, las plumas y los libros mencionados, vuela sobre ellos una figura que esquemáticamente sugiere al ángel de la fama, con una corona de olivo y una trompeta. Por supuesto, hay que recordar que los ángeles, seres de sexualidad ambigua, son una figura común en el repertorio homosexual de la época (recuérdese el "Nocturno de los ángeles" de Villaurrutia). La pluma que el personaje central lleva en la mano se repite sobre la lira que está en el suelo, en lo que puede verse como una metáfora visual de un pene que se aproxima a una cavidad: es obvia la resonancia con el título del grabado, Los anales, que da importancia central a 
este detalle a través del cual sc resume en este grabado la tradición, ya entonces larga (al menos tan vieja como el artículo de Gómez de Baquero), que relaciona el arte con la homosexualidad, pero añade la decisión de denigrar ambos. Los dos corazones traspasados por una flecha, en la parte superior derecha, constituyen otra metáfora del sexo anal, pues la redondez de los corazones repite en forma obvia la de las nalgas de los personajes y los muestra traspasados por una nada recóndita referencia fálica.

Además de representar a estos personajes como poetas burgueses, egocéntricos y estériles, el grabado acumula los detalles que los feminizan para acercar su posición devaluada a la de las mujeres, metáfora de lo desdeñable dentro de un patriarcado. El poema no toca este aspecto, aunque elabora las connotaciones de la esterilidad. No es dificil observar que los detalles feminoides del grabado son los decisivos en la caricaturización de estos personajes: sus nalgas son redondas y prominentes (lo que recuerda el apodo de Novo: "Nalgador Sobo"), el personaje que sostiene una flor, el que está a su izquierda y el central tienen finas cinturas y caderas redondeadas; el personaje central lleva un pañuelo atado al cuello, que se abulta para sugerir pechos turgentes. La flor está colocada frente a los genitales del personaje para sugerir una vulva. Los pantalones holgados y suaves del personaje a la extrema izquierda forman varios pliegues en su región genital y sugieren también un sexo femenino, en vez de mostrar el abultamiento del pene. Por último, los zapatos de todos los personajes son de tacón alto.

Quizá los ejemplos revisados en las páginas anteriores permiten una mejor comprensión de los contagios e infecciones literarias aludidos por el título. Durante las primeras décadas del siglo $\mathrm{XX}$, los temas relacionados con la homosexualidad están constreñidos a expresarse en un ambiente hostil, que coloca a los escritores en la disyuntiva de callar o elaborar subterfugios que cifran y deforman lo aludido, es decir, la homosexualidad que no puede narrarse ni poetizarse directamente. La infección latente en el libro es ese mensaje que el lector descifra con avidez, porque es el resultado de las restricciones represivas que constriñen al escritor. Numerosos poetas y narradores buscaron antídotos y curas para escapar de este estrecho territorio; entre ellos, Novo y Mujica Lainez exploraron las posibilidades de la sensibilidad camp. Pero como puede verse en la comparación del grabado de Orozco y "Elegía" de Novo, los mismos signos viajan entre antagonistas: si para Dorian Gray “el libro ponzoñoso" fue una metáfora del descubrimiento de la sexualidad, la imagen, al ser tomada por médicos y articulistas hostiles, sirve para categorizar la homosexualidad como patología. Y al cabo de tres décadas, esta metáfora ya vieja se convierte en arma de ataque político en el contexto de las polémicas nacionalistas en México. Mujica Lainez la retoma en la Argentina de los años 40, donde el libro también está habitado por una enfermedad que lo corroe. Pero también es posible que el libro ponzoñoso acumule su virulencia para dirigirla ya no contra el escritor, sino contra sus enemigos: en el prólogo a sus versiones españolas de los sonetos de Shakespeare, Mujica Lainez habla de la traducción como una estrategia de resistencia contra el régimen peronista.

Efectivamente, a lo largo de este artículo se han repetido las referencias a la traducción, quizá la práctica que más se asemeja a la actividad que, para seguir a 
Mujica Lainez, he llamado "subterfugio": el texto es resultado de cuidadosas estrategias de reformulación y adaptación que giran en torno al problema de todo traductor: cómo mediar entre los requerimientos del original y las necesidades del lector. El subterfugio también es similar a la traducción porque implica el conocimiento de otro lenguaje, compartido con otro escritor pero no con el lector, tal como un escritor homosexual tiene presente a cierto grupo de personas afines y está conciente de la diferencia de éstas respecto a algunos, o muchos, lectores. Esto apunta a otro aspecto del problema: la comunidad de escritores y lectores agrupados en torno al subterfugio, los que invocarán a Wilde y recordarán a Huysmans, son una cofradía internacional. Por eso la traducción es una metáfora tan útil en este contexto: señala la incierta posición del homosexual dentro de las fronteras nacionales, pero la reinterpreta como una posición de privilegio. El escritor homosexual que recurre al subterfugio, ubicado en una desahogada posición social y económica, se muestra dueño de lenguajes sofisticados, de una cultura cosmopolita, de códigos secretos compartidos por otras personas dueñas de talento y fama. Tanto en México como en Argentina, esa posición se afirmó a través del conocimiento de las literaturas europeas y de la posibilidad de leerlas y citarlas en sus idiomas originales, de traducirlas.

Es elocuente que, pese a estos privilegios que les permitieron escribir, los autores considerados aquí hayan insistido en metáforas de envenenamiento, infestación parasitaria y enfermedad, que, en un último análisis, revelan el poder de la represión y la hostilidad sobre la expresión literaria, aún para quienes disfrutaron de situaciones idóneas para ejercerla.

\section{Obras citadas}

Ellmann, Richard. 1988. Oscar Wilde. Nueva York: Vintage Books.

Huysmans, Joris-Karl. 1972. A rebours. París: Fasquelle.

Irwin, Robert Mackee. 2000. The Trials and Tribulations of Los Hijos de la Chingada.

Mexican Masculinities (1810-1960) Tesis doctoral inédita, New York University.

Molloy, Sylvia. 1998. "The Politics of Posing." Hispanisms and Homosexualities.

Durham: Duke University Press.

—_. "Of quotes and Queers: Citation Scenes in Latin American Literature" Artículo inédito.

Monsiváis, Carlos. 2000. Salvador Novo: lo marginal en el centro. México: Era.

Mujica Lainez, Manuel.1994. Cecil. Buenos Aires: Planeta.

_. 1990. El hombrecito del azulejo. Edición para niños con ilustraciones de Alejandro Ravassi. Buenos Aires: Editorial Sudamericana.

—_. 1968. Misteriosa Buenos Aires. Buenos Aires: Sudamericana.

Novo, Salvador. 1998. La estatua de sal. México: Consejo Nacional para la Cultura y las Artes.

—. 1977. Poesia. México: Fondo de Cultura Económica.

Wilde, Oscar. 1946. The Portable Oscar Wilde (The Picture of Dorian Gray, De Profundis, Salomé, The Importance of Being Earnest, plus Poems, Essays, Letters and Anecdotes). Nueva York: The Viking Press. 